NBER WORKING PAPER SERIES

\title{
TRADE OPENNESS, INVESTMENT INSTABILITY AND TERMS-OF-TRADE VOLATILITY
}

\author{
Assaf Razin \\ Efraim Sadka \\ Tarek Coury \\ Working Paper 9332 \\ http://www.nber.org/papers/w9332
NATIONAL BUREAU OF ECONOMIC RESEARCH
1050 Massachusetts Avenue \\ Cambridge, MA 02138 \\ November 2002
}

This paper is a revised version of Assaf Razin and Efraim Sadka, "Globalization and Investment: Differential Effects of Trade Openness and Capital Market Liberalization," Tel-Aviv University, 2001 (mimeo). The authors wish to thank Alan Auerbach, Elhanan Helpman, Mark Gertler, Maury Obstfeld, Bob Pindyck, two anonymous referees and Carlos Vegh for useful comments and suggestions. This version was completed while the first two authors were visiting CESifo, Munich. They wish to thank CESifo for its hospitality. This research was supported by the European Union Research Training Network, "Analyses of International Capital Markets: Understanding Europe's Role in the Global Economy." The views expressed herein are those of the authors and not necessarily those of the National Bureau of Economic Research.

(C) 2002 by Assaf Razin, Efraim Sadka, and Tarek Coury. All rights reserved. Short sections of text, not to exceed two paragraphs, may be quoted without explicit permission provided that full credit, including (C) notice, is given to the source. 
Trade Openness, Investment Instability and Terms-of-Trade Volatility Assaf Razin, Efraim Sadka, and Tarek Coury

NBER Working Paper No. 9332

November 2002

JEL No. F1, F3

\section{ABSTRACT}

In the presence of economies of scale in the investment technology, trade openness may have non-conventional effects on the level of investment, its cyclical behavior, and the volatility of the terms of trade. Trade openness may lead to boom-bust cycles of investment supported by self-fulfilling expectations. The economy may oscillate between "optimistic" expectations, "good" terms-of-trade and investment boom to "pessimistic" expectations, "bad" terms-of-trade and investment bust. We also suggest that the likelihood of such oscillations is higher for developing than for developed economies, because the former may typically incur higher setup costs of investment. This phenomenon may help to explain the excessive volatility of the terms of trade of developing countries, relative to industrial countries.

$\begin{array}{lll}\text { Assaf Razin } & \text { Efraim Sadka } & \text { Tarek Coury } \\ \text { Department of Economics } & \text { Department of Economics } & \text { Cornell University } \\ \text { Cornell University } & \text { Tel Aviv University } & \text { tc63@cornell.edu } \\ \text { Uris Building, \#402 } & \text { Tel Aviv, 69978 } & \\ \text { Ithaca, NY 14853 } & \text { Isreal } & \\ \text { and NBER } & \text { sadka@post.tau.ac.il } & \\ \text { razin@post.tau.ac.il } & \end{array}$




\section{Introduction}

The idea that "globalization may lead to instability" attracted the attention of the profession in recent years. A number of authors have demonstrated that increased capital mobility can be destabilizing in the sense that it increases the possibility of multiple selffulfilling expectations equilibria; see, for example, Lahiri (1999), Meng and Velasco (1999), Aghion, Bacchetta and Banerjee (1999), and Weder (2000).

In this body of the growth literature, some external economies (as may be associated, for instance, with human capital accumulation), may lead to multiplicity of equilibria. Capital account liberalization, which facilitates intertemporal consumption smoothing, increases the range of parameter values for which the multiple equilibria occur.

In the present paper we focus on the destabilizing effect of trade openness, which usually precedes capital account liberalization in the globalization process during economic development. We employ a "lumpy" adjustment cost for new investment, in the form of a fixed setup cost of investment. This specification, which has been recently supported empirically by Caballero and Engel (1999, 2000), creates economies of scale in investment. As a result, it tends to lump investment over time, in contrast to the more standard convex cost-of-adjustment specification, that leads to the spreading of investment spending over time. Trade openness may cause either appreciation or depreciation of the setup cost of investment, through changes in the terms of trade, and thereby may generate instability in the form of boom-bust investment cycles. It is demonstrated that this multiplicity of self-validating expectations equilibria (as it is triggered by terms-of-trade effects) is an intrinsic feature of trade openness.

The phenomenon of multiple equilibria may offer also some explanation for the high volatility of the terms of trade in developing countries. Indeed, studies over a long period of 30 
years show a markedly higher volatility of the terms of trade in developing countries, as compared to the developed (G-7) countries. For instance, Razin (1995) reports that the percentage standard deviation of the terms in trade in a developing country such as Mexico is 7fold higher than the corresponding deviation in a developed country such as Canada; see Table 1. Similar differences are reported also by Mendoza (1995). A traditional explanation for these differences is that the terms of trade in many developing countries are affected mostly by the prices of their export goods which consist to a significant extent of commodities (coffee, cocoa, etc.) traded in asset-like world markets where prices are typically volatile. This paper points out to a supplemental channel for such volatility. In developing countries, the infrastructure of communication, transportation, etc. is typically inadequate. Also, there is a scarcity of skilled, trained labor. Therefore, firms in these countries may have to incur a relatively high setup cost of training people, setting their own infrastructure, etc. when they invest. Such high setup costs are conducive to multiplicity of equilibria, which are reflected in highly volatile terms of trade.

Economies of scale either in the production or investment technologies are also a key contributor to the gains from trade and economic integration. For example, based on estimates taken from a partial equilibrium analysis, the Cecchini (1988) Report assesses that the gains from taking advantage of economies of scale will constitute about 30 percent of the total gains from the European market integration in 1992. Similarly, in a static general-equilibrium setting, Smith and Venables (1988) provide some industry simulations of the effects of the European integration, and find again a substantial role for economies of scale.

This paper, in essence, sheds a different light on the gains-from-trade implications of economies of scale. There could be indeed substantial gains from trade in an investment-boom 


\begin{tabular}{|c|c|}
\hline \multicolumn{2}{|c|}{ Table 1. Terms-of-Trade Volatility } \\
\hline$\underline{\text { Country }}$ & $\underline{\text { Percentage Standard Deviation }}$ \\
\hline \multicolumn{2}{|c|}{ Developed Countries, G-7 (1955-1990) } \\
\hline United States & 7.11 \\
\hline United Kingdom & 4.56 \\
\hline France & 5.38 \\
\hline Germany & 7.69 \\
\hline Italy & 7.83 \\
\hline Canada & 3.64 \\
\hline Japan & 14.77 \\
\hline \multicolumn{2}{|c|}{ Developing Countries (1961-1990) } \\
\hline Argentina & 26.84 \\
\hline Brazil & 27.33 \\
\hline Chile & 18.86 \\
\hline Mexico & 30.84 \\
\hline Peru & 26.57 \\
\hline Venezuela & 28.04 \\
\hline Israel & 11.77 \\
\hline Egypt & 17.35 \\
\hline Taiwan & 13.82 \\
\hline India & 18.29 \\
\hline Indonesia & 12.35 \\
\hline Korea & 16.19 \\
\hline Philippines & 13.93 \\
\hline Thailand & 13.16 \\
\hline Algeria & 23.83 \\
\hline Cameroon & 17.25 \\
\hline Zaire & 18.97 \\
\hline Kenya & 16.05 \\
\hline
\end{tabular}

Source: Razin (1995) 
equilibrium, but the gains could be meager or even negative in an investment-bust equilibrium.

The organization of the paper is as follows. Section 2 develops a model of a setup investment cost. Section 3 describes the consumption side of the model economy. The freetrade equilibrium is analyzed in Section 4. The destabilization effect of trade-openness is demonstrated in Section 5, for an exogenously given export demand function, and in Section 6 for a two-country model with endogenous export and import demand functions. Section 7 concludes.

\section{Lumpy Adjustment Costs of Investment}

Consider a two-good economy, and assume for simplicity that under free international trade the economy completely specializes in the production of one good, according to the standard Ricardian comparative advantage paradigm. To get first the intuition about the basic mechanism underlying the equilibrium level of investment, we initially assume that the demand for the country's export is exogenously given. In a subsequent section we will analyze a twocountry extension in which export demands are endogenously determined.

Specifically, suppose that the country is endowed with an initial amount, $\mathbf{x}_{\mathbf{0}}$, of good $\mathbf{x}$ and nothing of good $\mathbf{y}$. It can convert $\operatorname{good} \mathbf{x}$ into good $\mathbf{y}$ according to a Ricardian (linear) technology which is depicted by the line AB in Figure 1 . The slope of this line is $1 / \bar{p}$. (A reverse conversion of good $\mathbf{y}$ into good $\mathbf{x}$ is not possible.) The price of good $\mathbf{x}$ is chosen as a numeraire: $\mathbf{p}_{\mathbf{x}}=\mathbf{1}$. The world (and domestic) price of $\mathbf{y}$ is denoted by $\mathbf{p}$. We assume that $\mathbf{p}$ is smaller than $\overline{\mathrm{p}}$ (that is, $\mathbf{1} / \mathbf{p}>\mathbf{1} / \overline{\mathrm{p}}$ ), so that under free-trade the country will not produce good $\mathbf{y}$ at all, but only import this good. We refer to goods $\mathbf{x}$ and $\mathbf{y}$ as the export (domestic) and import 
(foreign) goods, respectively.

The technology of producing good $\mathbf{x}$ is a bit more complex. Suppose there exists a continuum of $\mathbf{N}$ firms in the $\mathbf{x}$ industry which differ from each other by a productivity index $\mathbf{g}$ We denote a firm which has a productivity index of $\mathbf{g}$ as an $\mathbf{g}$ firm. The cumulative distribution function of $\mathbf{g}$ is denoted by $\mathbf{G}(\bullet)$. With no loss of generality, we assume that the average value of the productivity index is zero, that is $\mathbf{E}(\mathbf{g}=\mathbf{0}$. For the sake of simplicity, we further normalize the initial number of firms to one; $\mathbf{N}=\mathbf{1}$. The number of each type of firm grows at the rate of population growth, $\mathbf{n}$, in order to fit the overlapping-generations framework in the next section.

The production process of good $\mathbf{x}$ lasts one period, so that if an $\mathbf{g}$ firm employs a stock of capital $\mathbf{K}$, it will generate a certain gross output flow (of the domestic good $\mathbf{x})$ of $\mathbf{F}(\mathbf{K})(\mathbf{1}+\mathbf{g}$, where $\mathbf{F}$ exhibits diminishing marginal productivity of capital, that is, $\mathbf{F}^{\mathbf{}}>\mathbf{0}, \mathbf{F}^{\prime \prime}<\mathbf{0}$. Naturally,

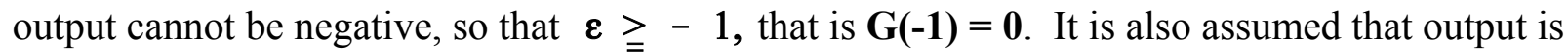
bounded from above, so that there exists $\bar{\varepsilon}$ such that $\mathrm{G}(\bar{\varepsilon})=1$; for simplicity, assume that $\bar{\varepsilon}=1$. We further assume for the sake of simplicity that capital fully depreciates at the end of the production process. Thus, at the start of each period the initial stock of capital is zero.

The domestic good x serves for both consumption, domestic investment, and exports. However, there is a fixed setup cost of investment which is carried out in good y and is therefore imported; ${ }^{5}$ in the subsequent two-country extension, we let this setup cost consist of the domestic good as well. The fixed cost is equal to $\mathbf{C}$ units of the import $\operatorname{good}(\mathbf{y})$.

${ }^{5}$ See Rothschild (1971) for one of the earliest analyses of such non-convex adjustment cost of investment. 
If an $\mathbf{g}$ firm invests an amount $\mathbf{K}$ in some period, it will have a capital stock of $\mathbf{K}$ and will generate in the next period a gross output of $\mathbf{F}(\mathbf{K})(\mathbf{1}+\mathbf{g}$ of good $\mathbf{x}$. The objective of an $\mathbf{g}$ firm is to maximize its value. That is, it chooses $\mathbf{K}$ so as to:

$$
\operatorname{Max}_{\mathrm{K}}\left\{\frac{\mathrm{F}(\mathrm{K})(1+\varepsilon)}{1+\mathrm{r}}-\mathrm{K}-\mathrm{pC}\right\}
$$

where $\mathbf{r}$ is the domestic rate of interest.

The first-order condition for the maximization of (1) yields the optimal $\mathbf{K}$ for an $\mathbf{g}$ firm as a function of $\mathbf{r}$, denoted by $\hat{\mathrm{K}}(\varepsilon, \mathbf{r})$. This $\hat{\mathrm{K}}(\varepsilon, \mathbf{r})$ is thus given implicitly by:

$$
\mathrm{F}^{\prime}[\hat{\mathrm{K}}(\varepsilon, \mathrm{r})](1+\varepsilon)=1+\mathrm{r},
$$

where $\mathbf{F}^{\prime}(\bullet)$ denotes the derivative of $\mathbf{F}(\bullet)$, the gross marginal product of capital.

Note, however, that the firm always has the option not to invest at all and avoid the setup cost $(\mathbf{C})$ of a new investment. Therefore, whether an $\mathbf{g}$-firm will indeed carry the new investment prescribed by equation (2) depends on whether its productivity is high enough so as to more than cover the fixed setup cost required for new investments. That is, the $\mathrm{g}$-firm will indeed carry on the investment prescribed by the first-order condition (2), if and only if:

$$
\frac{\mathrm{F}[\hat{\mathrm{K}}(\varepsilon, \mathrm{r})](1+\varepsilon)}{1+\mathrm{r}}-[\hat{\mathrm{K}}(\varepsilon, \mathrm{r})+\mathrm{pC}] \geqq 0
$$

Therefore, there exists a cutoff level of $\mathbf{g}$ denoted by $\mathbf{g}$, so that an $\mathbf{g}$-firm will invest, if and only if $\varepsilon \geqq \varepsilon_{0}$. The cutoff level of $g$ is defined by: 


$$
\mathrm{F}\left[\hat{\mathrm{K}}\left(\varepsilon_{0}, \mathrm{r}\right)\right]\left(1+\varepsilon_{0}\right)=(1+\mathrm{r})\left[\hat{\mathrm{K}}\left(\varepsilon_{0}, \mathrm{r}\right)+\mathrm{pC}\right]
$$

The left-hand side of equation (3) is the output generated by the new investment. The right-hand side is the (future value of the) capital cost of this investment, which consists of a variable cost, $\hat{\mathrm{K}}(\boldsymbol{\varepsilon}, \mathrm{r})$, and a setup cost, $\mathbf{p C}$.

While the marginal productivity condition (2) determines the level of investment that each firm will undertake (if it chooses to do so), condition (3) can be viewed as determining whether or not to invest at all. Firms with a productivity index larger than $\mathbf{g}_{\mathrm{o}}$ would indeed make new investment. But firms with a productivity index below $\mathbf{g}_{\text {o }}$ will make no new investment.

Another way of describing the decision whether or not to invest is obtained by substituting equation (2) into equation (3) to get:

$$
\left(1+\varepsilon_{0}\right)\left\{\mathrm{F}\left[\hat{\mathrm{K}}\left(\varepsilon_{0}, \mathrm{r}\right)\right]-\mathrm{F}^{\prime}\left[\hat{\mathrm{K}}\left(\varepsilon_{0}, \mathrm{r}\right)\right] \hat{\mathrm{K}}\left(\varepsilon_{0}, \mathrm{r}\right)\right\}=(1+\mathrm{r}) \mathrm{pC}
$$

Equation (3') thus states that the infra-marginal incremental output generated by the new investment [namely, the left-hand-side of equation (3')] must equal (the future value of) the setup cost; see Figure 2. Thus, an $\mathbf{g}$ firm will choose $\hat{\mathrm{K}}(\varepsilon, \mathrm{r})$ as its optimal stock of capital, if its productivity index is above $\mathbf{g}_{\text {; }}$ otherwise, it will not invest or produce at all. Therefore, the optimal stock of capital for an $\mathbf{g}$ firm, denoted by $\mathbf{K}(\mathbf{g} \mathbf{r})$, is generally given by:

$$
\mathrm{K}(\varepsilon, \mathrm{r})= \begin{cases}\hat{\mathrm{K}}(\varepsilon, \mathrm{r}) & \text { if } \varepsilon \geqq \varepsilon_{0} \\ 0 & \text { if } \varepsilon \leqq \varepsilon_{0}\end{cases}
$$




\section{Consumption}

Consider now an overlapping-generations model with a representative consumer who lives for two periods and a population growth rate of $n$. The individual consumes two goods in each of the two periods, so that altogether she consumes four goods: $\mathbf{c}_{\mathrm{x} 1}, \mathbf{c}_{\mathrm{y} 1}, \mathbf{c}_{\mathrm{x} 2}$, and $\mathbf{c}_{\mathbf{y} 2}$, where $\mathbf{c}_{\mathrm{ji}}$ is consumption of good $\mathbf{j}=\mathbf{x}, \mathbf{y}$ in the ith period of her life, $\mathbf{i}=\mathbf{1 , 2}$. She is endowed in the first period of her life with $\mathbf{x}_{\mathbf{0}}$ units of the domestic good. For the sake of simplicity, we consider a time-separable, Cobb-Douglas utility function with a subjective discount factor 2:

$$
\mathrm{u}\left(\mathrm{c}_{\mathrm{x} 1}, \mathrm{c}_{\mathrm{y} 1}, \mathrm{c}_{\mathrm{x} 2}, \mathrm{c}_{\mathrm{y} 2}\right)=\left[\alpha \ln \mathrm{c}_{\mathrm{x} 1}+(1-\alpha) \ln \mathrm{c}_{\mathrm{y} 1}\right]+\theta\left[\alpha \ln \mathrm{c}_{\mathrm{x} 2}+(1-\alpha) \ln \mathrm{c}_{\mathrm{y} 2}\right]
$$

where " is the share of the domestic good in each period in the total consumption of that same period.

As usual, this utility function gives rise to the following demand functions:

$$
\begin{gathered}
\mathrm{c}_{\mathrm{x} 1}=\alpha \mathrm{W} /(1+\theta) \\
\mathrm{c}_{\mathrm{y} 1}=(1-\alpha) \theta \mathrm{W} /(1+\theta) \mathrm{p} \\
\mathrm{c}_{\mathrm{x} 2}=\alpha \theta \mathrm{W}(1+\mathrm{r}) /(1+\theta), \\
\mathrm{c}_{\mathrm{y} 2}=(1-\alpha) \theta \mathrm{W}(1+\mathrm{r}) /(1+\theta) \mathrm{p}
\end{gathered}
$$

where $\mathbf{W}$ is the present value of life-time income (wealth) at birth. Note that, as we shall 
consider a steady state, the price (p) of the foreign good remains constant over time and $\mathbf{W}$ is the same for both the old and the young.

In each period there is a new generation of firms whose gis distributed according to $\mathbf{G}$. These firms are owned by the newly-born generation. Therefore, the wealth of a representative consumer is the present value of the profits of these firms. Thus, the wealth of a representative young individual is:

$$
\mathrm{W}=\mathrm{x}_{0}+\frac{1}{1+\mathrm{r}} \int_{\varepsilon_{0}}^{1} \mathrm{~F}[\mathrm{~K}(\varepsilon, \mathrm{r})](1+\varepsilon) \mathrm{dG}(\varepsilon)-\int_{\varepsilon_{0}}^{1}[\mathrm{~K}(\varepsilon, \mathrm{r})+\mathrm{pC}] \mathrm{dG}(\varepsilon),
$$

which can be rewritten as:

$$
\mathrm{W}=\mathrm{x}_{0}+\frac{1}{1+\mathrm{r}} \int_{\varepsilon_{0}}^{1} \mathrm{~F}[\mathrm{~K}(\varepsilon, \mathrm{r})](1+\varepsilon) \mathrm{dG}(\varepsilon)-\int_{\varepsilon_{0}}^{1} \mathrm{~K}(\varepsilon, \mathrm{r}) \mathrm{dG}(\varepsilon)-\mathrm{pC}\left[1-\mathrm{G}\left(\varepsilon_{0}\right)\right] .
$$

[Recall that only the firms with a productivity index above $\mathbf{g}_{\text {, }}$ carry out new investment, and the number of such firms per young individual is $\mathbf{1}-\mathbf{G}\left(\mathbf{g}_{0}\right)$.]

\section{Free-Trade Equilibrium}

The economy is open to free trade in goods as was already mentioned, but we assume that it does not have an access to the world capital markets. However, there are domestic financial intermediaries that lend or take deposits at a fixed rate. ${ }^{6}$ We assume that there is an exogenously given downward-sloping demand curve for the country's export, reflecting some market power for the home country in the world markets. Denote the foreign demand function

${ }^{6}$ These intermediaries play the role of "the social contrivance of money" in Samuelson's (1958) formulation. 
for good $\mathbf{x}$ per young individual by $\mathbf{D}(\mathbf{p})$. As $\mathbf{p}$ is the relative price of $\mathbf{y}$, it follows that as $\mathbf{p}$ rises, the demand for $\mathbf{x}$ rises too, so that $\mathbf{D}^{\prime}(\mathbf{p})>\mathbf{0}$.

In order to complete the description of the steady state of this economy, it remains to specify the equilibrium conditions in the markets for the two goods ( $\mathbf{x}$ and $\mathbf{y}$ ). Market clearing in the domestic good $(\mathbf{x})$ requires that domestic consumption of both the young (namely, $\mathbf{c}_{\mathbf{x} 1}$ ) and the old [namely, $\mathbf{c}_{\mathbf{x} 2}(\mathbf{1}+\mathbf{n})^{-1}$, per young individual], plus the domestic component of investment [namely, $\int_{\varepsilon_{0}}^{1} \mathrm{~K}(\varepsilon, \mathrm{r}) \mathrm{dG}(\varepsilon)$ ], plus exports [namely, $\mathbf{D}(\mathbf{p})$ ] must equal domestic output [namely, $(\mathbf{1}+\mathbf{n})^{-1} \int_{\varepsilon_{0}}^{1} \mathrm{~F}[\mathrm{~K}(\varepsilon, \mathrm{r})] \mathrm{dG}(\varepsilon)$, per young individual], plus the initial endowment (namely, $\mathbf{x}_{\mathbf{0}}$ ). That is:

$$
\begin{aligned}
\frac{\alpha \mathrm{W}}{1+\theta} & +\frac{\alpha \theta \mathrm{W}(1+\mathrm{r})}{(1+\theta)(1+\mathrm{n})}+\int_{\varepsilon_{0}}^{1} \mathrm{~K}(\varepsilon, \mathrm{r}) \mathrm{dG}(\varepsilon) \\
& +\mathrm{D}(\mathrm{p})=\frac{1}{1+\mathrm{n}} \int_{\varepsilon_{0}}^{1} \mathrm{~F}[\mathrm{~K}(\varepsilon, \mathrm{r})] \mathrm{dG}(\varepsilon)+\mathrm{x}_{0} .
\end{aligned}
$$

Because the home country has no access to foreign capital markets, the import of the foreign good is determined by the value of exports of the domestic good, as trade in goods must be balanced period-by-period. The imports of the foreign good in each period are equal to domestic consumption of the young (namely, $\mathbf{c}_{\mathrm{y} 1}$ ), and the old [namely, $\mathbf{c}_{\mathrm{y} 2}(\mathbf{1}+\mathbf{n})^{-1}$, per young individual,] plus the setup cost which is exclusively imported (namely, [1 - G(g) $] \mathbf{C})$. Note that only firms with productivity index $\mathbf{g}$ above $\mathbf{g}$, make new investment and incur the setup cost $\mathbf{C}$; the number of such firms per young individual is $\mathbf{1}-\mathbf{G}\left(\mathbf{g}_{\mathrm{f}}\right)$. Exports of $\mathbf{D}(\mathbf{p})$ units of the domestic good can finance imports of $\mathbf{D}(\mathbf{p}) / \mathbf{p}$ units of the foreign good. Therefore: 


$$
\frac{(1-\alpha) W}{(1+\theta) p}+\frac{(1-\alpha) \theta W(1+r)}{(1+\theta) p(1+n)}+\left[1-G\left(\varepsilon_{0}\right)\right] C=\frac{D(p)}{p} .
$$

This completes the description of the market equilibrium in the trade-open economy.

There are four endogenous variables - $\mathbf{W}, \mathbf{p}, \mathbf{r}$, and $\mathbf{g}_{\mathbf{0}}$ - and four equations - (3), (7), (8) and (9).

Note that $\mathbf{K}(\mathbf{g r})$ is defined implicitly by the first-order condition, equation (2), and equation (4).

Naturally, for an economy with financial intermediaries, we shall focus our attention on the golden-rule (efficient) steady-state equilibrium in which the rate of interest (namely, $\mathbf{r}$ ) will be equal to the rate of population growth (namely, $\mathbf{n}$ ); this rate is known as the "biological" rate of interest. To see that this is indeed an equilibrium, note that by employing equation (7) we can rewrite equation (8) as:

$$
\begin{gathered}
\frac{\alpha \mathrm{W}}{1+\theta}+\frac{\alpha \theta \mathrm{W}(1+\mathrm{r})}{1+\theta)(1+\mathrm{n})}-\mathrm{W}-\frac{\mathrm{r}-\mathrm{n}}{(1+\mathrm{r})(1+\mathrm{n})} \int_{\varepsilon_{0}}^{1} \mathrm{~F}[\mathrm{~K}(\varepsilon, \mathrm{r})] \mathrm{dG}(\varepsilon) \\
-\left[1-\mathrm{G}\left(\varepsilon_{0}\right)\right] \mathrm{pC}+\mathrm{D}(\mathrm{p})=0 .
\end{gathered}
$$

Now, by adding up equations ( 8 ') and (9) we get:

$$
\frac{\theta \mathrm{W}(\mathrm{r}-\mathrm{n})(1+\mathrm{r})}{1+\theta}=(\mathrm{r}-\mathrm{n}) \int_{\varepsilon_{0}}^{1} \mathrm{~F}[\mathrm{~K}(\varepsilon, \mathrm{r})] \mathrm{dG}(\varepsilon)
$$

Thus, the golden rule (namely, $\mathbf{r}=\mathbf{n}$ ) is indeed an equilibrium steady state. ${ }^{7}$

Because of the setup cost of a new investment, low-productivity firms may not find it

${ }^{7}$ But, as Gale (1973) pointed out, there is another steady state equilibrium in which $\mathbf{r} . . \mathbf{n}$. In this case the term $\mathbf{r}-\mathbf{n}$ cancels out on both sides of equation (10), and it follows that the value of second-period consumption of each individual [namely, $2 W(1+r) /(1+2)]$ is equal to the output that accrues to that individual in the second period [namely, $\int_{\varepsilon_{0}}^{1} F[K(\varepsilon, r) d G(\varepsilon)]$. This situation is termed by Gale as autarky vis-a-vis the young and the old. 
worthwhile to carry out a new investment. On the other hand, very high-productivity firms are likely to invest, depending on the setup cost $\mathbf{p C}$. That is, as long as $\mathbf{G}\left(\mathbf{g}_{\mathbf{0}}\right)<\mathbf{1}$, there will be a positive mass of firms (namely, the firms with $\mathbf{g} \$ \mathbf{g}_{\text {o }}$ ) that will carry out new investment. The endogenously determined cutoff $\mathbf{g}$ (namely, $\mathbf{g}_{\mathbf{0}}$ ) depends crucially on the setup cost $\mathbf{p} \mathbf{C}$. If $\mathbf{p C}$ is high enough, then no firm will carry out a new investment, that is the endogenously-determined $\mathbf{g}_{\mathrm{o}}$ is equal to (or exceeds) $1 .{ }^{8}$

\section{Trade-Openness and Boom-Bust Investment Cycles: Exogenous Export Demand}

Does trade-openness introduce instability? Put differently: Does the trade-open economy have more than one self-fulfilling expectations equilibrium, some with "pessimistic" expectations and "low" investment ("bust" equilibria) and others with "optimistic" expectations and "high" investments ("boom" equilibria)? Furthermore, is this multiplicity of equilibria a distinct feature of trade openness?

First, note that the phenomenon of multiple equilibria does not occur under autarky. Under autarky, the Ricardian (linear) technology of producing y, which is depicted in Figure 1, nails down a unique relative price $\overline{\mathrm{p}}$ of good $\mathbf{y}$. Then, the marginal productivity condition, equation (2), and the cutoff condition equation (3), uniquely determine the autarkic level of investment and the cutoff $\mathbf{g}$ (recall that $\mathbf{r}=\mathbf{n}$ ). Thus, the autarkic equilibrium is unique. ${ }^{9}$

${ }^{8}$ More realistically, there may be other sectors of the economy with different investment technologies that carry out new investment and generate capital accumulation and growth; our one-industry economy is obviously a theoretical simplification.

${ }^{9}$ Note that the uniqueness result carries over to the more general case of a convex production possibility set (as in the Hecksher-Ohlin framework). Suppose that $\bar{p}$ is an equilibrium. Now, a lower price of $\mathbf{y}$ will increase the number of investing firms (namely, will 
However, the domestic technology of producing $\mathbf{y}$ is old relative to the existing modern world technology. That is $\overline{\mathrm{p}}$ is "very much" higher than p; see Figure 1. Put differently, the domestic economy has a comparative disadvantage in producing $\mathbf{y}$. Hence, opening up the economy to trade in goods induces it to specialize à-la-Ricardo in producing $\mathrm{x}$ and benefit from the modern world technology of producing $\mathbf{y}$, by importing $\mathbf{y}$.

Second, multiple equilibria may well exist under free international trade. In order to gain some insight into the possibility of such a multiplicity of equilibria, consider the cutoff condition, equation (3), and the trade-balance condition, equation (9). Suppose that the 4-tuple, $\varepsilon_{0}=\varepsilon_{0}^{0}, \mathrm{p}=\mathrm{p}^{0}, \mathbf{W}=\mathbf{W}^{0}$ and $\mathbf{r}=\mathbf{n}$, constitutes an equilibrium. Consider now a lower foreign good price (p). This reduces the domestic value (pC) of the setup cost $(\mathbf{C})$, and, as can be seen from equation (3), it will induce more firms to make new investments. That is, a lower $\mathbf{p}$ may reduce the cutoff level $\mathbf{g}_{0}$ below $\varepsilon_{0}^{0}$, so that the proportion $\mathbf{1}-\mathbf{G}\left(\mathbf{g}_{0}\right)$ of investing firms rises. For such a change to occur, the economy must also have higher export revenues $[$ namely, $\mathbf{D}(\mathbf{p}) / \mathbf{p})]$ in order to finance the new imports of the foreign good (namely, $\left[\mathbf{1}-\mathbf{G}\left(\mathbf{g}_{0}\right)\right] \mathbf{C}$ ), required for the setup cost and the increased domestic consumption demand for the foreign good (because of its lower price).

To see that this demand indeed increases, substitute for $\mathbf{W}$ [from equation (7)] in the trade-balance equation (9), to get:

lower $\mathbf{g}_{\mathbf{0}}$ ), and therefore the investment demand for $\mathbf{y}$; it will also boost the consumption demand for $\mathbf{y}$. At the same time, because of the convexity of the production possibility set, the supply of $\mathbf{y}$ will shrink, thus creating an excess demand for $\mathbf{y}$. Similarly, a higher price of $\mathbf{y}$ will generate an excess supply of $\mathbf{y}$. Thus, the equilibrium must be unique. 


$$
\begin{gathered}
\frac{(1-\alpha)\left[1+\theta(1+\mathrm{r})(1+\mathrm{n})^{-1}\right] \mathrm{Z}\left(\varepsilon_{0}, \mathrm{r}\right)}{(1+\theta) \mathrm{p}}+\left\{1-\frac{(1-\alpha)\left[1+\theta(1+\mathrm{r})(1+\mathrm{n})^{-1}\right.}{1+\theta}\right\} \\
{\left[1-\mathrm{G}\left(\varepsilon_{0}\right)\right] \mathrm{C}=\frac{\mathrm{D}(\mathrm{p})}{\mathrm{p}}}
\end{gathered}
$$

where:

$$
\mathrm{Z}\left(\varepsilon_{0}, \mathrm{r}\right)=\mathrm{x}_{0}+\frac{1}{1+\mathrm{r}} \int_{\varepsilon_{0}}^{1} \mathrm{~F}[\mathrm{~K}(\varepsilon, \mathrm{r})](1+\varepsilon) \mathrm{dG}(\varepsilon)-\int_{\varepsilon_{0}}^{1} \mathrm{~K}(\varepsilon, \mathrm{r}) \mathrm{dG}(\mathrm{E})
$$

Indeed, one can see from equation (11) that a lower $\mathbf{p}$ boosts domestic consumption demand for the foreign good. ${ }^{10}$

Now, if export revenues $\mathbf{D}(\mathbf{p}) / \mathbf{p}$ indeed increase when $\mathbf{p}$ falls, then there may exist another equilibrium with a lower $\mathbf{p}$ (below $\mathbf{p}^{0}$ ) and a lower $\mathbf{g}_{\text {(below }} \boldsymbol{\varepsilon}_{0}^{0}$ ) with a higher proportion of firms making new investments. Thus, the possibility of a multiple equilibria seems to rest on the price elasticity of the foreign demand for the country's exports. If this demand is inelastic, then indeed a decline in $\mathbf{p}$ will generate higher export revenues. ${ }^{11}$ (Note that the price of the domestic good is $\mathbf{1} / \mathbf{p}$, so that a decline in $\mathbf{p}$ means an increase in the price of the domestic good; and if the foreign demand for the domestic good is inelastic, then indeed an increase in its price raises export revenues.)

We establish the possibility of multiple equilibria by numerical simulations. We specify a uniform distribution of gover the interval $[-1,1]$, so that $\mathbf{G}(\mathbf{g}=(\mathbf{1}+\mathbf{g} / \mathbf{2}$ for $\mathbf{g},[-\mathbf{1}, \mathbf{1}]$. The

\footnotetext{
${ }^{10}$ Recall that $\mathbf{r}=\mathbf{n}$, so that the term multiplying $\left[\mathbf{1}-\mathbf{G}\left(\mathbf{g}_{0}\right)\right] \mathbf{C}$ on the left hand side of equation (11) reduces to " $>\mathbf{0}$.

${ }^{11}$ Note that even though the aggregate foreign demand for the country's export may be inelastic, still each domestic firm is atomistically small and faces a perfectly elastic demand.
} 
production function is of the Cobb-Douglas form $\mathbf{F}(\mathbf{K})=\mathbf{K}^{\$}$, where $\$$ is the capital share in GNP. The foreign demand for the domestic good is specified as $\mathbf{D}(\mathbf{p})=(\mathbf{a}+\mathbf{p})^{\mathrm{F}}$, with both $\mathbf{a}$ and $\mathbf{F}$ being positive. The simulations are depicted in Figure 3. For a range of valus of $\mathbf{C}$, there are (at least) two equilibria: One with a high $\mathbf{p}$, a high $\mathbf{g}_{\text {o }}$ and low investment (the "bust" equilibrium), and another with a low $\mathbf{p}$, a low $\mathbf{g}$, and high investment (the "boom" equilibrium).

Our simple model suggests that the trade-open economy is plagued by an endogenously determined "boom" and "bust" investment cycles. Optimistic expectations regarding the terms of trade (namely, $\mathbf{1} / \mathbf{p}$ ) are self-validated by low setup costs (namely $\mathbf{p C}$ ), high investment, high exports, high export revenues, and low p. On the other hand, pessimistic expectations regarding the terms of trade are also self-validated by high setup costs, low investment, low exports, low export revenues, and high $\mathbf{p}$. It should be emphasized again that, as we have already pointed out, this multiplicity of equilibria is an intrinsic feature of opening up the economy, because in the closed (autarkic) economy the equilibrium is unique.

\section{Trade Openness and Boom-Bust Investment Cycles: Endogenous Export Demand}

A key mechanism behind the instability (multiplicity) of equilibria brought about by globalization is the small elasticity (less than one) of the exogenously given demand for the country's export. In this case, only a price effect plays a role in generating the instability because there is no income effect with this demand function. Indeed, inelastic demands are not unusual in certain industries. ${ }^{12}$ In general, however, demand facing exports of small developing

${ }^{12}$ In general, the demand facing exports of small developed countries is fairly low (unlike the textbook paradigm of a small country), but still above one. For example, a widely cited survey by Goldstein and Khan (1985) puts this elasticity in the range of 1.0-1.6 for Austria, 
countries, though fairly inelastic, still has an elasticity above one. Nevertheless, the instability associated with globalization is not confined to the "partial-equilibrium" specification of an exogenously given demand for the country's exports. In such a partial equilibrium setting, only a price effect plays a role in generating instability. In this section we extend our analysis to a general-equilibrium, two-country ("home" country and "foreign" country) model in which both income and price effects play a role in shaping the demand for a country's exports.

We continue to assume complete specialization under free trade. Specifically, the technology of converting good $\mathbf{x}$ into good $\mathbf{y}$, which is depicted in Figure 1, continues to apply to the home country. For the foreign country, the opposite is true: it can convert good $\mathbf{y}$ into $\operatorname{good} \mathbf{x}$ by a Ricardian (linear) technology with a rate of transformation of $\mathbf{y}$ to $\mathbf{x}$ equaling $\overline{\mathrm{p}}^{*}$. We assume that $\overline{\mathrm{p}}>\overline{\mathrm{p}}^{*}$, so that the home country has a comparative advantage in producing good $\mathbf{x}$ and the foreign country has a comparative advantage in producing good $\mathbf{y}$. Hence, in any freetrade equilibrium, the relative price of $\mathbf{y}$ will be between $\overline{\mathrm{p}}$ and $\overline{\mathrm{p}}^{*}$. The initial endowments are $\left(\mathbf{x}_{0}, \mathbf{y}_{0}\right)$ and $\left(\mathrm{x}_{0}{ }^{*}, \mathrm{y}_{0}^{*}\right)$ in the home and foreign country, respectively. These are in addition to the ownership of the firms in each country by the residents of that country.

We now specify a more general technology for the setup cost of investment as follows.

Belgium and Denmark. However, this elasticity refers to aggregate measures of exports, but for a specific export good things may be different. An inelastic demand for a country's certain export good can arise, when the country is a major supplier of this good in the world market. One can think of at least three categories of such goods: energy, commodities, and high-tech products. Indeed, Robert Pindyck (1979) estimated the demand elasticity of various energy products to be significantly below one in the short run, but about one or even a bit higher in the long-run. (For instance, 0.15-0.30 for residential and industrial demand for oil.) Similarly, Pindyck (1978) estimated the demand elasticity for a commodity such as bauxite (used to produce aluminum) to be extremely small, about $0.05-0.10$. However, estimates of elasticity of demand for high-tech products, such as semiconductors [Irwin and Klenow (1994)] and computers [Gordon (2000)] are higher than one, between 1.5 and 2.0. 
(We refer to the home country; the specification for the foreign country is similar with asterisks in the notation.) There is a minimal setup input $\left(\mathbf{C}_{\mathbf{0}}\right)$, where this input is produced by inputs $L_{\mathbf{x}}$ and $L_{\mathbf{y}}$ of good $\mathbf{x}$ and good $\mathbf{y}$, respectively, according to a constant-returns-to-scale technology: $\mathbf{H}\left(L_{\mathbf{x}}, \mathrm{L}_{\mathrm{y}}\right)$.

Each investing firm chooses $L_{\mathbf{x}}$ and $L_{\mathbf{y}}$ so as to minimize the setup cost, $L_{\mathbf{x}}+\mathbf{p} \mathrm{L}_{\mathbf{y}}$ subject to $\mathbf{H}\left(L_{\mathbf{x}}, \mathrm{L}_{\mathbf{y}}\right) \geqq \mathbf{C}_{\mathbf{0}}$. The minimizing inputs of $\mathbf{x}$ and $\mathbf{y}$ are denoted by $\mathbf{V}_{\mathbf{x}}\left(\mathbf{p}, \mathbf{C}_{\mathbf{0}}\right)$ and $\mathbf{V}_{\mathbf{y}}\left(\mathbf{p}, \mathbf{C}_{\mathbf{0}}\right)$, respectively, and the minimal setup cost is denoted by:

$$
\mathrm{C}\left(\mathrm{p}, \mathrm{C}_{0}\right)=\mathrm{V}_{\mathrm{x}}\left(\mathrm{p}, \mathrm{C}_{0}\right)+\mathrm{pV} \mathrm{y}\left(\mathrm{p}, \mathrm{C}_{0}\right)
$$

in units of good $\mathbf{x}$. For the foreign country, the minimal setup cost is denoted by:

$$
\mathrm{C}^{*}\left(\mathrm{p}, \mathrm{C}_{0}^{*}\right)=\frac{1}{\mathrm{p}} \mathrm{V}_{\mathrm{x}}^{*}\left(\mathrm{p}, \mathrm{C}_{0}^{*}\right)+\mathrm{V}_{\mathrm{y}}^{*}\left(\mathrm{p}, \mathrm{C}_{0}^{*}\right)
$$

in units of good $\mathbf{y}$. (Note that it is the same $\mathbf{p}$, namely the free-trade equilibrium price of $\mathbf{y}$, that appears in the minimal setup cost equation in both countries.) The cutoff levels of $\mathbf{g}$ in the home and foreign country, that is $g_{0}$ and $\varepsilon_{0}^{*}$, respectively, are now defined implicitly by: ${ }^{13}$

$$
\mathrm{F}\left[\hat{\mathrm{K}}\left(\varepsilon_{0}, \mathrm{r}\right)\right]\left(1+\varepsilon_{0}\right)=(1+\mathrm{r})\left[\hat{\mathrm{K}}\left(\varepsilon_{0}, \mathrm{r}\right)+\mathrm{C}\left(\mathrm{p}, \mathrm{C}_{0}\right)\right]
$$

and

$$
\mathrm{F}^{*}\left[\hat{\mathrm{K}}^{*}\left(\varepsilon_{0}^{*}, \mathrm{r}^{*}\right)\right]\left(1+\varepsilon_{0}^{*}\right)=\left(1+\mathrm{r}^{*}\right)\left[\hat{\mathrm{K}}^{*}\left(\varepsilon_{0}^{*}, \mathrm{r}\right)+\mathrm{C}^{*}\left(\mathrm{p}, \mathrm{C}_{0}^{*}\right)\right]
$$

${ }^{13}$ Note that the investment technology in the home country requires investments in units of good $\mathbf{x}$ in order to produce good $\mathbf{x}$, whereas in the foreign country it requires investments in units of good $\mathbf{y}$ in order to produce good $\mathbf{y}$. 
The representative utility function in the home country is given by equation (5), whereas the representative utility function in the foreign country is given by:

$$
\mathrm{u}^{*}\left(\mathrm{c}_{\mathrm{x} 1}^{*}, \mathrm{c}_{\mathrm{y} 1}^{*}, \mathrm{c}_{\mathrm{x} 2}^{*}, \mathrm{c}_{\mathrm{y} 2}^{*}\right)=\left[\alpha^{*} \operatorname{lnc}_{\mathrm{x} 1}^{*}+\left(1-\alpha^{*}\right) \ln \mathrm{c}_{\mathrm{y} 1}^{*}\right]+\theta^{*}\left[\alpha^{*} \ln \mathrm{x}_{\mathrm{x} 2}^{*}+\left(1-\alpha^{*}\right) \ln \mathrm{c}_{\mathrm{y} 2}^{*}\right]
$$

Similarly, the home country demand functions are given by equations (6a) - (6d), whereas the demand functions in the foreign country are given by the same equations with $\mathbf{2}^{*}$, " $^{*}, \mathbf{r}^{*}$ and $\mathbf{W}^{*}$ replacing 2 , ", $\mathbf{r}$ and $\mathbf{W}$, respectively. The specifications of $\mathbf{W}$ and $\mathbf{W}^{*}$ are now given by:

$$
\begin{aligned}
\mathrm{W} & =\mathrm{x}_{0}+\mathrm{py}_{0}+\frac{1}{1+\mathrm{r}} \int_{\varepsilon_{0}}^{1} \mathrm{~F}[\mathrm{~K}(\varepsilon, \mathrm{r})](1+\varepsilon) \mathrm{dG}(\varepsilon) \\
& -\int_{\varepsilon_{0}}^{1} \mathrm{~K}(\varepsilon, \mathrm{r}) \mathrm{dG}(\varepsilon)-\mathrm{C}\left(\mathrm{p}, \mathrm{C}_{0}\right)\left[1-\mathrm{G}\left(\varepsilon_{0}\right)\right]
\end{aligned}
$$

and

$$
\begin{aligned}
\mathrm{W}^{*} & =\mathrm{x}_{0}^{*}+\mathrm{py}_{0}^{*}+\frac{\mathrm{p}}{1+\mathrm{r}^{*}} \int_{\varepsilon_{0}^{*}}^{1} \mathrm{~F}^{*}\left[\mathrm{~K}^{*}\left(\varepsilon, \mathrm{r}^{*}\right)\right](1+\varepsilon) \mathrm{dG}^{*}(\varepsilon) \\
& -\mathrm{p} \int_{\varepsilon_{0}^{*}}^{1} \mathrm{~K}^{*}\left(\varepsilon, \mathrm{r}^{*}\right) \mathrm{dG}^{*}(\varepsilon)-\mathrm{pC}^{*}\left(\mathrm{p}, \mathrm{C}_{0}^{*}\right)\left[1-\mathrm{G}^{*}\left(\varepsilon_{0}^{*}\right)\right],
\end{aligned}
$$

respectively.

The free-trade market clearing equations for $\operatorname{good} \mathbf{x}$ and good $\mathbf{y}$ are given respectively, by: 


$$
\begin{aligned}
\frac{\alpha \mathrm{W}}{1+\theta}+\frac{\alpha \theta \mathrm{W}(1+\mathrm{r})}{(1+\theta)(1+\mathrm{n})} & +\int_{\varepsilon_{0}}^{1} \mathrm{~K}(\varepsilon, \mathrm{r}) \mathrm{dG}(\varepsilon)+\mathrm{V}_{\mathrm{x}}\left(\mathrm{p}, \mathrm{C}_{0}\right)\left[1-\mathrm{G}\left(\varepsilon_{0}\right)\right] \\
& +\frac{\alpha^{*} \mathrm{~W}^{*}}{1+\theta^{*}}+\frac{\alpha^{*} \theta^{*} \mathrm{~W}^{*}\left(1+\mathrm{r}^{*}\right)}{\left(1+\theta^{*}\right)\left(1+\mathrm{n}^{*}\right)}+\mathrm{V}_{\mathrm{x}}^{*}\left(\mathrm{p}, \mathrm{C}_{0}^{*}\right)\left[1-\mathrm{G}^{*}\left(\varepsilon_{0}^{*}\right)\right] \\
& =\mathrm{x}_{0}+\frac{1}{1+\mathrm{n}} \int_{\varepsilon_{0}}^{1} \mathrm{~F}[\mathrm{~K}(\varepsilon, \mathrm{r})] \mathrm{dG}(\varepsilon)+\mathrm{x}_{0}^{*},
\end{aligned}
$$

and

$$
\begin{aligned}
\frac{(1-\alpha) \mathrm{W}}{(1+\theta) \mathrm{p}} & +\frac{(1-\alpha) \theta \mathrm{W}(1+\mathrm{r})}{(1+\theta) \mathrm{p}(1+\mathrm{n})}+\mathrm{V}_{\mathrm{y}}\left(\mathrm{p}, \mathrm{C}_{0}\right)\left[1-\mathrm{G}\left(\varepsilon_{0}\right)\right] \\
& +\frac{\left(1-\alpha^{*}\right) \mathrm{W}^{*}}{\left(1+\theta^{*}\right) \mathrm{p}}+\frac{\left(1-\alpha^{*}\right) \theta^{*} \mathrm{~W}^{*}\left(1+\mathrm{r}^{*}\right)}{\left(1+\theta^{*}\right) \mathrm{p}\left(1+\mathrm{n}^{*}\right)}+\int_{\varepsilon_{0}^{*}}^{1} \mathrm{~K}^{*}\left(\varepsilon, \mathrm{r}^{*}\right) \mathrm{dG}^{*}(\varepsilon) \\
& +\mathrm{V}_{\mathrm{y}}^{*}\left(\mathrm{p}, \mathrm{C}_{0}^{*}\right)\left[1-\mathrm{G}^{*}\left(\varepsilon_{0}^{*}\right)\right]=\mathrm{y}_{0}+\mathrm{y}_{0}^{*}+\frac{1}{1+\mathrm{n}^{*}} \int_{\varepsilon_{0}^{*}}^{1} \mathrm{~F}^{*}\left[\mathrm{~K}^{*}\left(\varepsilon, \mathrm{r}^{*}\right)\right] \mathrm{dG}^{*}(\varepsilon)
\end{aligned}
$$

In this case too we focus on the golden-rule (efficient) steady-state equilibrium in which $\mathbf{r}=\mathbf{n}$ and $\mathbf{r}^{*}=\mathbf{n}^{*}{ }^{14}$

We establish the existence of multiple equilibria via numerical simulations. The setup technologies are taken to be of the Constant-Elasticity-of-Substitution (CES) form:

$$
\mathrm{H}\left(\mathrm{v}_{\mathrm{x}}, \mathrm{v}_{\mathrm{y}}\right)=\left[\mathrm{b} v_{\mathrm{x}}^{\rho}+(1-\mathrm{b}) \mathrm{v}_{\mathrm{y}}^{\rho}\right]^{1 / \rho}
$$

for the home country, and

${ }^{14}$ Note that we are only assuming trade openness and not free capital mobility, so that the interest rates in the two countries are not necessarily equal to each other. 


$$
\mathrm{H}^{*}\left(\mathrm{v}_{\mathrm{x}}^{*}, \mathrm{v}_{\mathrm{y}}^{*}\right)=\left[\mathrm{b}^{*} \mathrm{v}_{\mathrm{x}}^{* \rho}+\left(1-\mathrm{b}^{*}\right) \mathrm{v}_{\mathrm{y}}^{* \rho}\right]^{1 / \rho *}
$$

for the foreign country. Upon proper substitutions, an equilibrium with a positive number of investing firms in both countries (that is, both $\mathrm{g}_{\mathrm{g}}$ and $\varepsilon_{0}^{*}$ below one) is defined by a single (reduced-form) excess demand equation of good $\mathbf{x}$, denoted by $\mathbf{E}(\mathbf{p})=\mathbf{0}$, in the inverse of the terms-of-trade variable $\mathbf{p}$. The derivation of this equation is delegated to the appendix, where we also draw the graph of $\mathbf{E}(\mathbf{p})$ and show its multiple roots.

Figure 4 depicts three different equilibrium relative prices of good $\mathbf{y}$ (namely, p) for a range of the parameter $\mathbf{C}_{0}$, the minimal setup input for investment in the export industry (x) in the home country. The corresponding input in the foreign country $\left(\mathrm{C}_{0}^{*}\right)$ is held constant. This figure not only demonstrates the existence of multiple equilibria, but also that the range of equilibrium prices widens as the minimal setup input for investment in the export industry (namely, $\mathbf{C}_{\mathbf{0}}$ ) rises; starting with a unique equilibrium for low values of $\mathbf{C}_{0}{ }^{15}$ The range of equilibrium prices is in a sense a measure of the volatility of the terms of trade. This figure captures the idea that developed countries with low values of $\mathbf{C}_{\mathbf{0}}$ have very little terms-of-trade volatility, whereas developing countries with high values of $\mathbf{C}_{\mathbf{0}}$ have high terms-of-trade volatility; see Table 1.

Figure 5 illustrates the multiplicity of equilibria for a range of consumption shares of the export good and import good in the home country (namely, " and 1-"). The consumption shares of the two good (" " and $\mathbf{1}-$ " ") in the foreign country are kept constant. This figure

\footnotetext{
${ }^{15} \mathrm{We}$ ignore the middle equilibrium price in this discussion, as this price is unstable in an auctioneer-type process of price adjustment; see the appendix.
} 
captures the effect of demand-side differences between the two countries on the terms of trade and their volatility.

We have thus established the instability introduced by trade openness under endogenously-determined demand functions for imports and exports, derived from fairly common utility and production functions.

\section{Concluding Remarks}

In the presence of economies of scale in the investment technology, trade openness may have non-conventional effects on the level of investment and its cyclical behavior. Trade openness may lead to a discrete "jump" in the level of investment, as it may trigger a discrete price change and specialization. In the presence of economies of scale, such a shift creates a sizeable boost in aggregate investment. But trade openness may also lead to boom-bust cycles of investment (namely, multiple equilibria) supported by self-fulfilling expectations. ${ }^{16}$ In this sense, globalization destabilizes the economy. The economy may oscillate between "optimistic" expectations, "good" terms of trade and investment boom to "pessimistic" expectations, "bad" terms of trade and investment bust. ${ }^{17}$ We also suggest that the likelihood of such oscillations is higher for developing than for developed economies, because the former may typically incur higher setup costs of investment. This phenomenon may help to explain the excessive volatility of the terms of trade of developing countries.

\footnotetext{
${ }^{16}$ Investment cycles may be driven also by other mechanisms, such as balance-sheet effects; see Krugman (2000).

${ }^{17} \mathrm{An}$ interesting issue, yet to be investigated, is whether it is desirable to try to use trade policy to prevent the boom-bust cycles.
} 
Our analysis also sheds new light on the implications of economies of scale for the gains from trade argument. There could be substantial gains in the investment-boom equilibrium. However, gains could be small and even negative in the investment-bust equilibrium.

\section{Appendix: Derivation of the Equilibrium in a Two-Country Model}

With a Cobb-Douglas production function, $\mathbf{F}(\mathbf{K})=\mathbf{K}^{\$}$, the capital stock function of the investing firms in the home country, as derived from equation (2), is given by:

$$
\hat{\mathrm{K}}(\varepsilon, r)=\left[\frac{\beta(1+\varepsilon)}{1+\mathrm{r}}\right] \frac{1}{1-\beta}
$$

With the CES form [equation (17)] for the setup technologies, we can derive the minimizing input requirement functions and the minimal setup cost function as follows:

$$
\begin{aligned}
& \mathrm{V}_{\mathrm{x}}\left(\mathrm{p}, \mathrm{C}_{0}\right)=\frac{\mathrm{C}_{0} \phi(\mathrm{p})}{\left[\mathrm{b} \phi(\mathrm{p})^{\rho}+(1-\mathrm{b})\right]^{1 / \rho}} \\
& \mathrm{V}_{\mathrm{y}}\left(\mathrm{p}, \mathrm{C}_{0}\right)=\frac{\mathrm{C}_{0}}{\left[\mathrm{~b} \phi(\mathrm{p})^{\rho}+(1-\mathrm{b})\right]^{1 / \rho}}
\end{aligned}
$$

and

$$
\mathrm{C}\left(\mathrm{p}, \mathrm{C}_{0}\right)=\frac{\mathrm{C}_{0}[\phi(\mathrm{p})+\mathrm{p}]}{\left[\mathrm{b} \phi(\mathrm{p})^{\rho}+(1-\mathrm{b})\right]^{1 / \rho}}
$$


where

$$
\phi(p)=\left(\frac{p b}{1-b}\right)^{\frac{1}{1-\rho}} .
$$

With a uniform distribution of $\mathbf{g}$ [namely, $\mathbf{G}(\mathbf{g})=(1+9) / 2$ ], the cutoff level of $\mathbf{g}$ as derived from equation (3), is as follows [employing equation (A1)]:

$$
\varepsilon_{0}=\left[\frac{\mathrm{C}_{0}[\phi(\mathrm{p})+\mathrm{p}]}{\gamma\left[\mathrm{b} \phi(\mathrm{p})^{\rho}+(1-\mathrm{b})\right]^{1 / \rho}}\right]^{1-\beta}-1,
$$

where

$$
\gamma=\left(\frac{\beta^{\beta}}{1+\mathrm{r}}\right)^{\frac{1}{1-\beta}}-\left(\frac{\beta}{1+\mathrm{r}}\right)^{\frac{1}{1-\beta}} .
$$

The wealth of a representative individual, as defined in equation (14), is given by:

$$
\begin{aligned}
\mathrm{W}=\mathrm{x}_{0}+\mathrm{py}_{0}+ & \left(\frac{1-\beta}{2-\beta}\right)\left[\frac{1}{1+\mathrm{r}}\left(\frac{\beta}{1+\mathrm{r}}\right)^{\frac{\beta}{1-\beta}}+\left(\frac{\beta}{1+\mathrm{r}}\right)^{\frac{1}{1-\beta}}\right] \\
& {\left[2^{\frac{2-\beta}{1-\beta}}-\left(1+\varepsilon_{0}\right)^{\frac{2-\beta}{1-\beta}}\right]-\frac{\left(1-\varepsilon_{0}\right) \mathrm{C}_{0}[\phi(\mathrm{p})+\mathrm{p}]}{2\left[\mathrm{~b} \phi(\mathrm{p})^{\rho}+(1-\mathrm{b})\right]^{1 / \mathrm{p}}} . }
\end{aligned}
$$

The analogous equations for the foreign country are given by equations (A1) - (A8) with

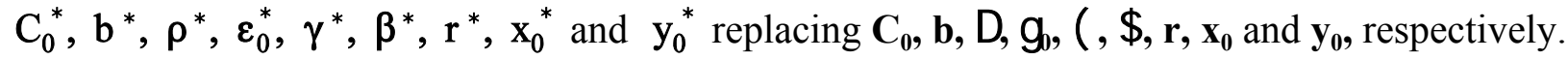


Substituting equations (A1) - (A8) and their foreign country counterparts in either one of the two market clearing equations, (15) and (16), yield a single (reduced-form) world excess demand equation for good $\mathbf{x}, \mathbf{E}(\mathbf{p})$, in the inverse of the terms of trade variable, $\mathbf{p}$. The graph of $\mathbf{E}(\mathbf{p})$ is depicted in Figure 1A. For the parameter values specified in this figure, we have three roots (solutions to the equation $\mathbf{E}(\mathbf{p})=\mathbf{0}): \mathbf{p}=\mathbf{0 . 8}, \mathbf{1 . 6}$, and 1.4. Note that $\mathbf{E}(\mathbf{p})$ is decreasing in $\mathbf{p}$ in the neighborhood of the middle root. If one perceives a process of a price adjustment conducted by an auctioneer, who raises the price of a good whenever there is an excess demand for it, and announces a lower price whenever there is an excess supply, then the middle price is unstable. To see this, note that $\mathbf{p}$ is the inverse of the relative price of $\mathbf{x}$. If $\mathbf{p}$ falls below the middle price $(\mathbf{p}=\mathbf{1 . 8})$, then there arises an excess demand of $\mathbf{x}$, and the auctioneer will raise the relative price of $\mathbf{x}$; that is, the auctioneer will lower $\mathbf{p}$, moving further away from equilibrium. Similarly, when $\mathbf{p}$ rises above the middle price, the auctioneer will move it further away from equilibrium. In this sense, the middle equilibrium price is unstable. 


\section{References}

[1] Aghion, Philippe, Bacchetta, Philippe, and Abhijit Banerjee (1999), "Financial

Liberalization and Volatility in Emerging Market Economies," in P.R. Agenor, M.

Miller, D. Vines, and A. Weber (editors), The Asian Financial Crises: Causes,

Contagion and Consequences, Cambridge University Press; published under the wrong title, "Capital Markets and the Instability of Open Economies."

[2] Caballero, Ricardo and Eduardo M. Engel (2000), "Lumpy Adjustment and Aggregate

Investment Equations: A 'Simple' Approach Relying on $\mathbf{Q}$ and Cash Flows' Information," mimeo.

[3] Caballero, Ricardo and Eduardo M. Engel (1999), "Explaining Investment Dynamics in US Manufacturing: A Generalized (S;s) Approach," Econometrica, July, 741-82.

[4] Cecchini, Paolo, with Michael Catinat and Alexis Jacquemin (1988), The European

Challenge: 1992, The Benefits of a Single Market, Wildwood House.

[5] Gale, David (1973), "Pure Exchange Equilibrium of Dynamic Economic Models," Journal of Economic Theory, Vol. 6, 12-36.

[6] Goldstein, Morris and Mohsin S. Khan (1985), "Income and Price Effects in Foreign Trade," in Jones, Ron W. and Peter B. Kenen (eds.), Handbook of International Economics, Vol. 2, Ch. 20, North-Holland.

[7] Gordon, Robert J. (2000), "Does the 'New Economy' Measure Up to the Great Inventions of the Past?", Journal of Economic Perspectives, Vol. 14 (4), Fall. 
[8] Irwin, Douglas A. and Peter J. Klenow (1994), "Learning-by-Doing Spillovers in the Semiconductor Industry," Journal of Political Economy, 1200-1227.

[9] Krugman, Paul (2000), "Balance Sheets, the Transfer Problem, and Financial Crises," in Isard Peter, Assaf Razin, and Andrew K. Rose (eds.), International Finance and Financial Crises: Essays in Honor of Robert P. Flood, Jr., Kluwer Academic Publishers and the International Monetary Fund.

[10] Lahiri, Amartya (1999), "Growth and Equilibrium Indeterminancy: The Role of Capital Mobility," UCLA, mimeo.

[11] Mendoza, Enrique G. (1995), "The Terms of Trade, the Real Exchange Rate, and Economic Fluctuations", International Economic Review, 36(1), February, 101-37.

[12] Meng, Qinglai and Andres Velasco (1999), "Can Capital Mobility be Destabilizing?", NBER Working Paper \#7263, July.

[13] Pindyck, Robert (1979), The Structure of World Energy Demand, MIT Press.

[14] ----------(1978), "The Gains to Producers from Cartelization of World Commodity Markets," Review of Economics and Statistics.

[15] Razin, Assaf (1995), "The Dynamic-Optimizing Approach to the Current Account: Theory and Evidence," in Peter B. Kenen (Editor), Understanding Interdependence: The Macroeconomics of the Open Economy, Princeton University Press.

[16] Rothschild, Michael (1971), "On the Cost of Adjustment," Quarterly Journal of Economics, Vol. 85(4), November, 605-622.

[17] Samuelson, Paul A. (1958), "An Exact Consumption-Loan Model of Interest with or without the Social Contrivance of Money," Journal of Political Economy, Vol. 66, 467- 
482.

[18] Smith Alasdair and Anthony J. Venables (1988), "Completing the Internal Market in the European Community: Some Industry Simulations," European Economic Review, Vol. $32(7), 1501-1525$ 


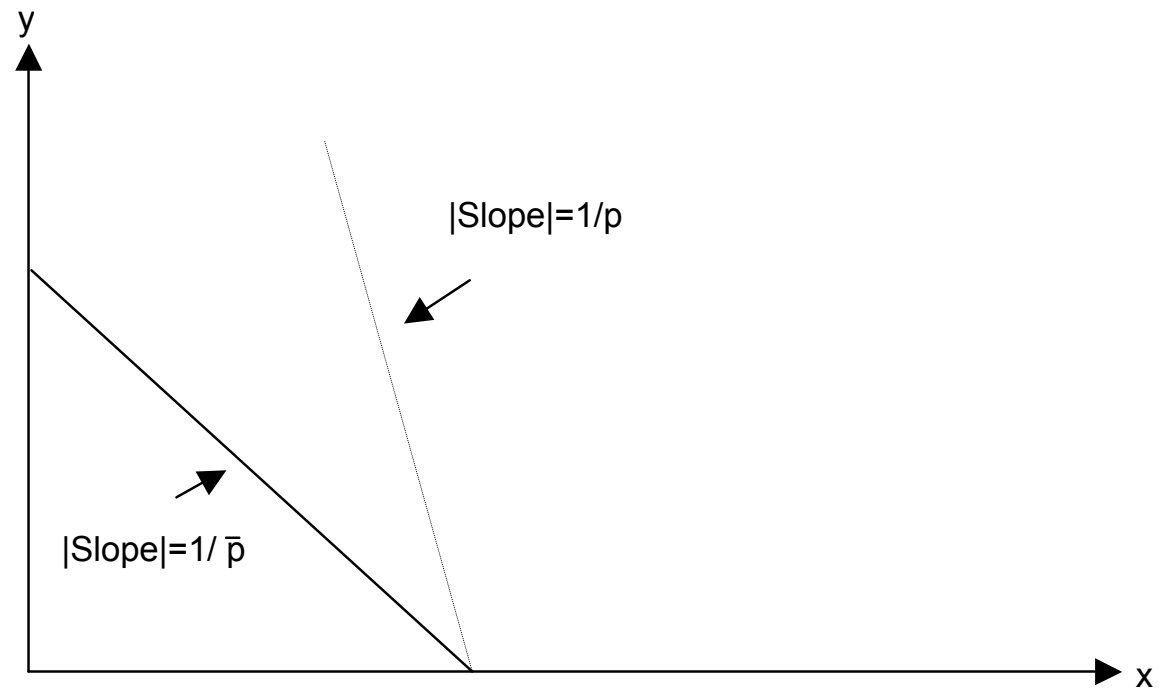

Figure 1: A Ricardian (Linear) Technology of Converting good $x$ into good $y$ 


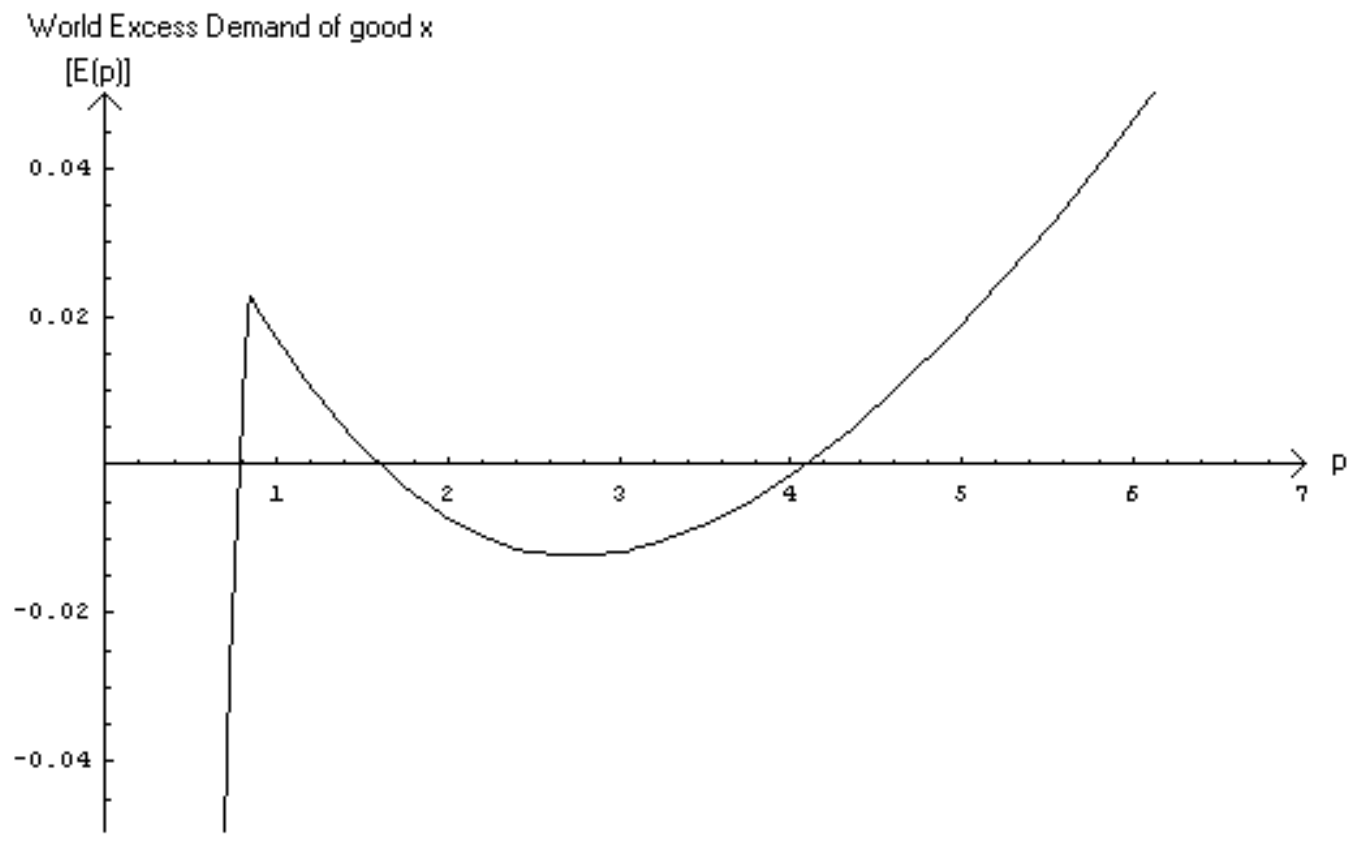

Figure 1a: Multiple roots of $E(p)$.

Notes:

$$
\begin{aligned}
& \beta=\beta^{*}=0.33, n=n^{*}=0, \theta=\theta^{*}=0.5 \\
& \alpha=\alpha^{*}=0.5, x_{0}+x_{0}^{*}=0.62, y_{0}+y_{0}^{*}=0.1, \\
& \eta=\eta^{*}=0.5, C_{0}=0.6, C_{0}^{*}=0.3
\end{aligned}
$$

(Notice that because the two countries have the same homothetic preferences, the distribution of the initial endowments between them is irrelevant for the equilibrium prices.) 


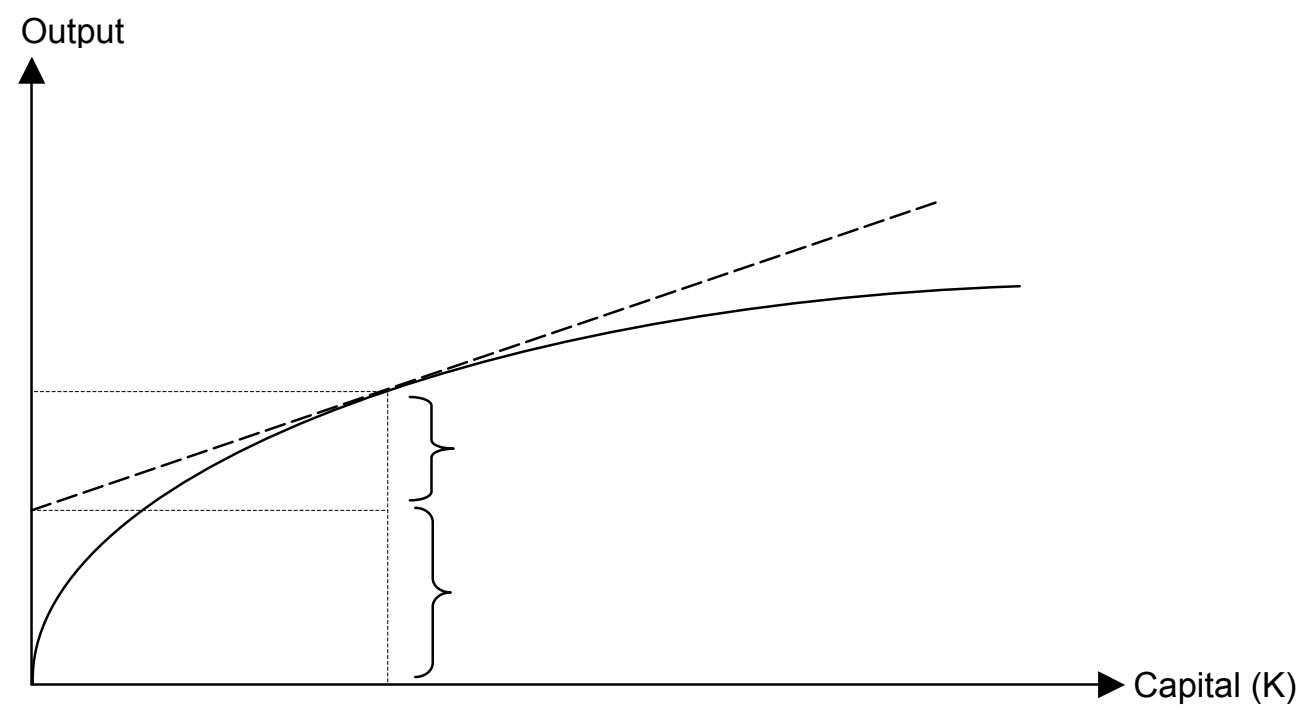

Figure 2: The Determination of the Cutoff Productivity Level 


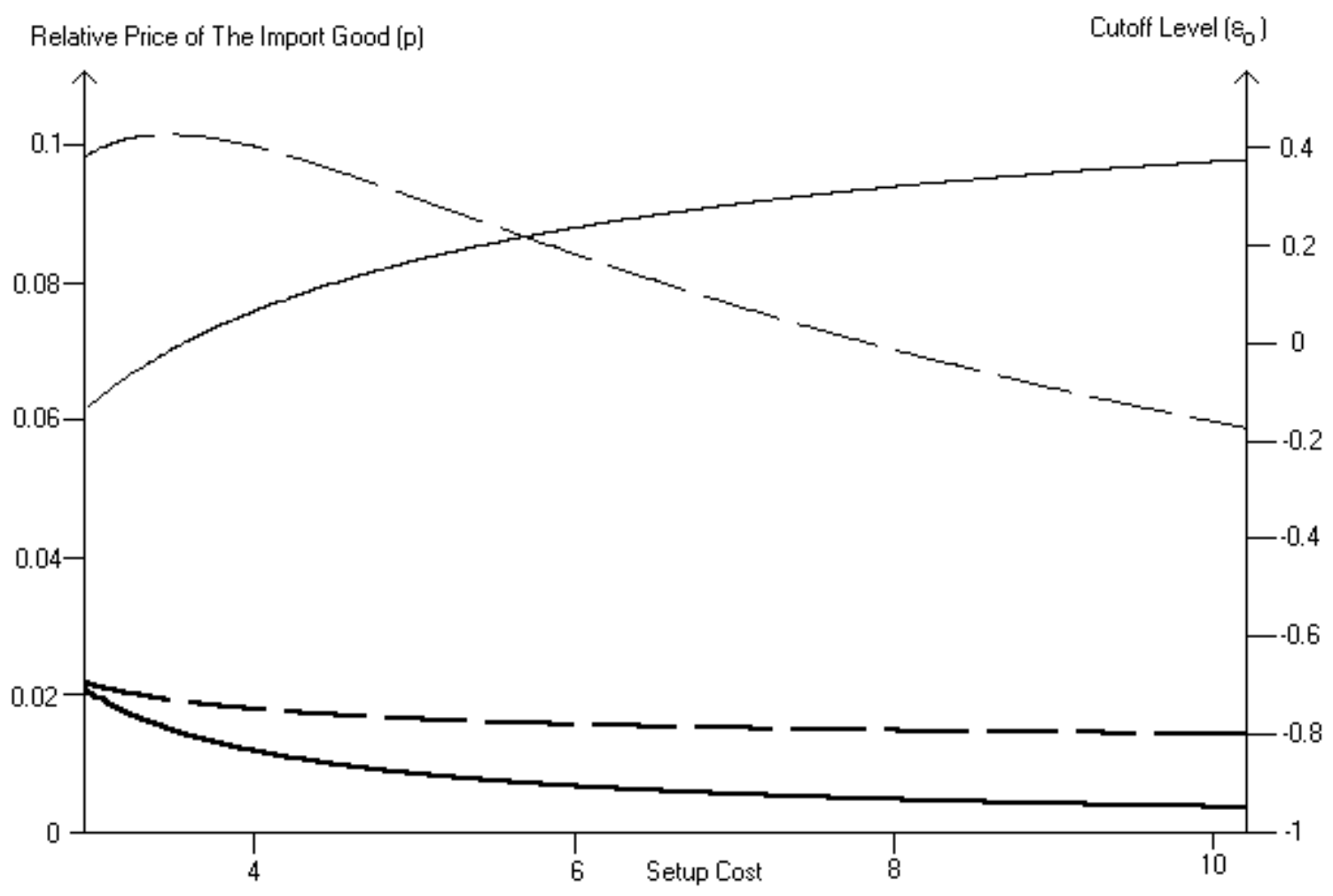

Figure 3: Multiple equilibria for various values of the setup cost: Exogenous export Demand.

Notes: $\varepsilon$ is distributed uniformly over $[-1,1]$

$$
\sigma=0.3, a=0.35, \beta=0.33, x_{0}=1, \theta=0.5, n=0
$$

The solid lines depict $\mathrm{p}$; the dashed lines depict $\varepsilon_{0}$. 


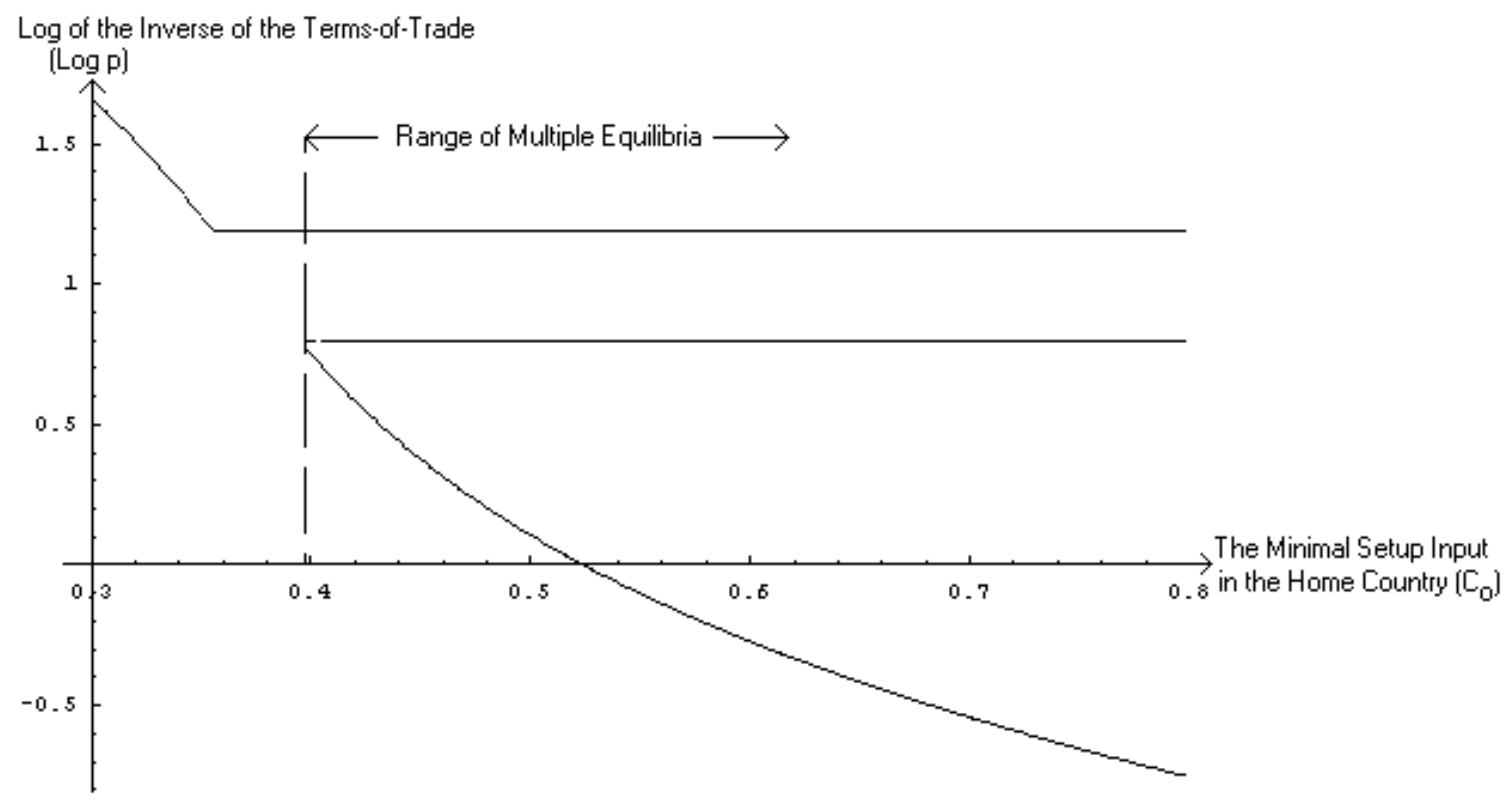

Figure 4: Multiple equilibria under free trade in a two-country model; A varying setup cost $\left(C_{0}\right)$.

Notes: The parameter values are:

$$
\begin{aligned}
& \beta=\beta^{*}=0.33, n=n^{*}=0, \theta=\theta^{*}=0.5 \\
& \alpha=\alpha^{*}=0.5, x_{0}+x_{0}^{*}=0.62, y_{0}+y_{0}^{*}=0.1, \\
& \eta=\eta^{*}=0.5, C_{0}^{*}=0.3
\end{aligned}
$$

(Notice that because the two countries have the same homothetic preferences, the distribution of the initial endowments between them is irrelevant for the equilibrium prices.) 


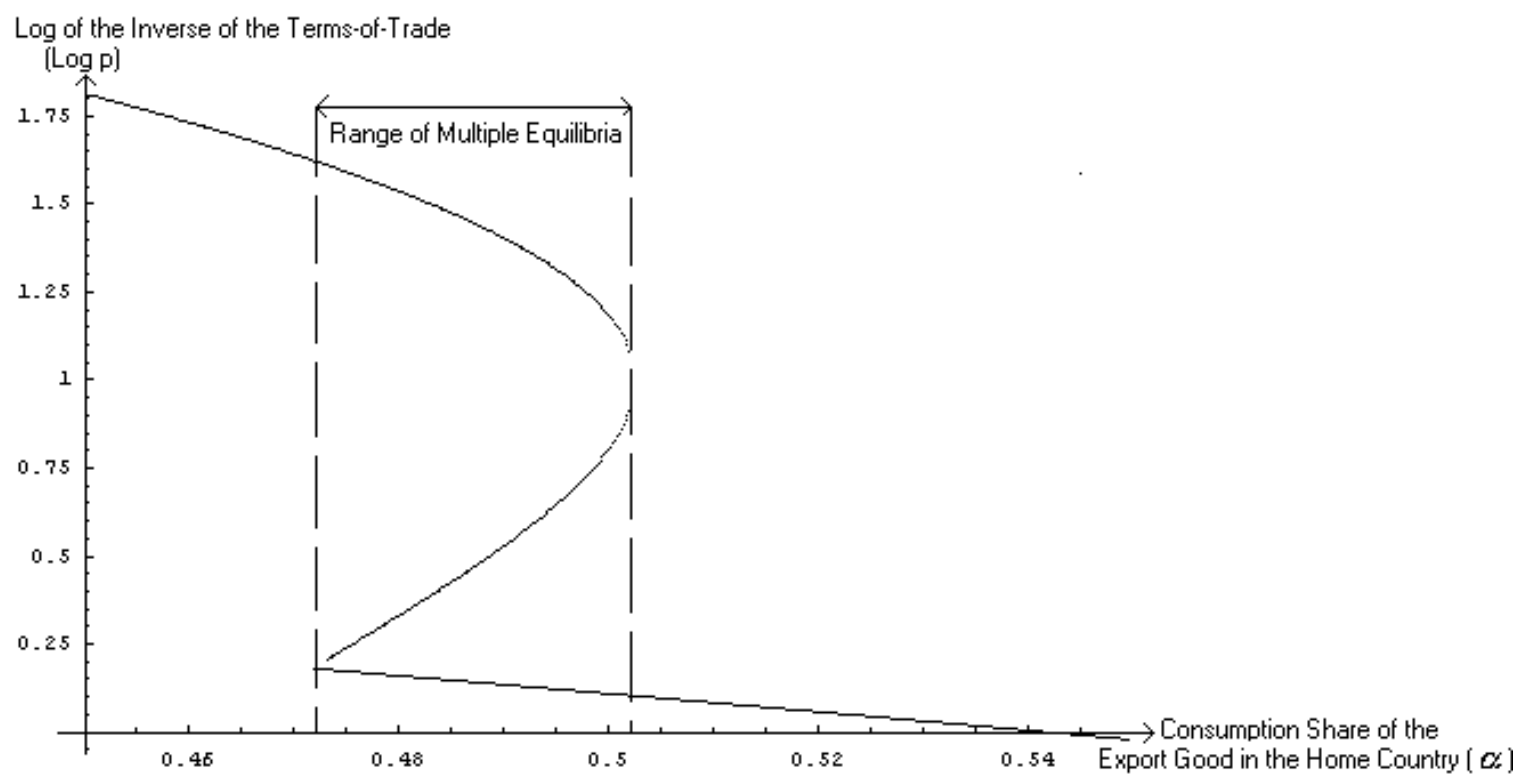

Figure 5: Multiple equilibria under free trade in a two-country model; A varying consumption share of good $x$ in the home country.

Notes: The parameter values are:

$$
\begin{aligned}
& \beta=\beta^{*}=0.33, n=n^{*}=0, \theta=\theta^{*}=0.5 \\
& \alpha^{*}=0.5, x_{0}+x_{0}^{*}=0.62, y_{0}+y_{0}^{*}=0.1, \\
& \eta=\eta^{*}=0.5, C_{0}^{*}=0.3
\end{aligned}
$$

(Notice that because the two countries have the same homothetic preferences, the distribution of the initial endowments between them is irrelevant for the equilibrium prices.) 


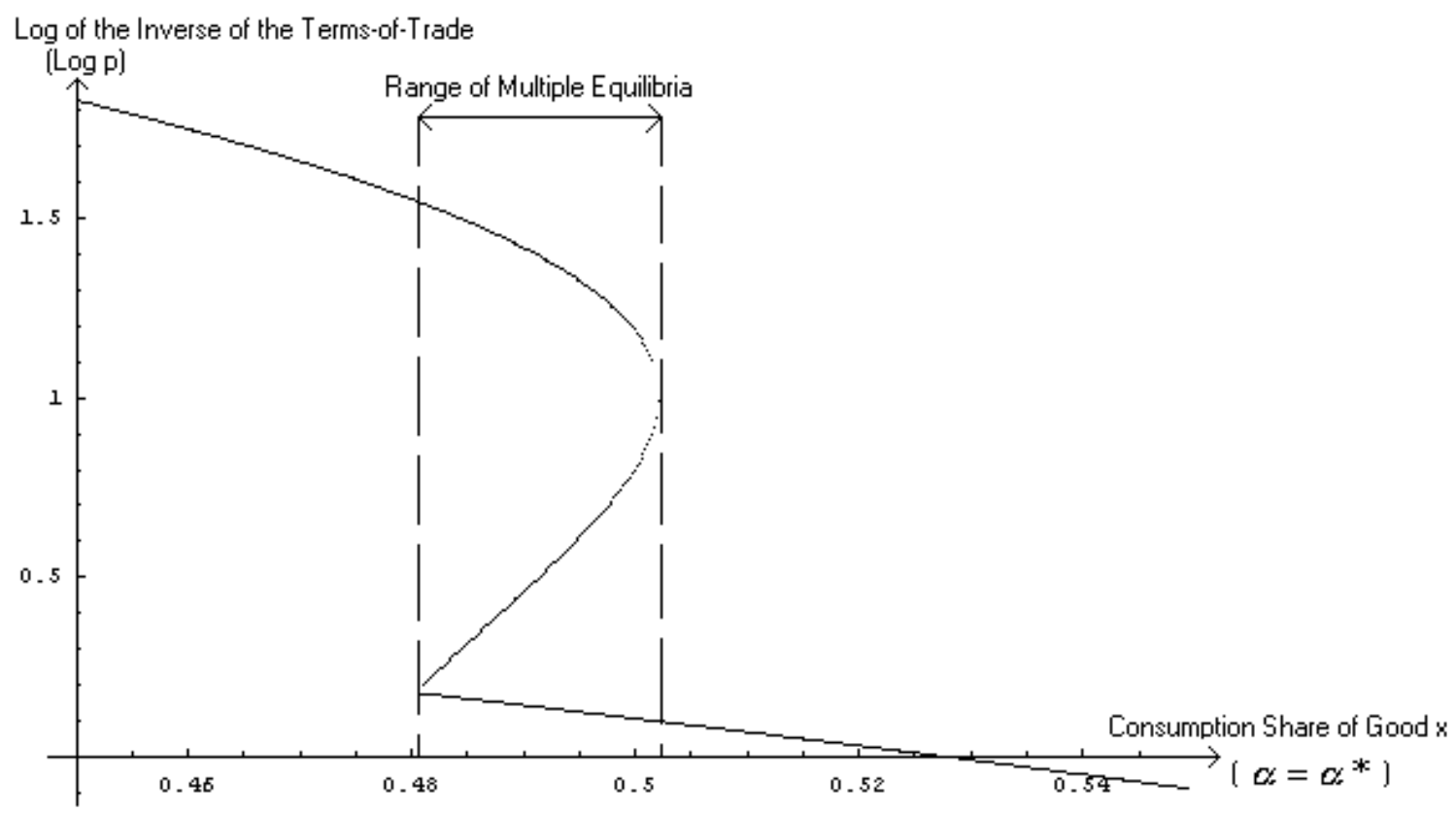

Figure 6: Multiple equilibria under free trade in a two-country model; A varying consumption share of good $\mathrm{x}$.

Notes: The parameter values are:

$$
\begin{aligned}
& \beta=\beta^{*}=0.33, n=n^{*}=0, \theta=\theta^{*}=0.5 \\
& x_{0}+x_{0}^{*}=0.62, \quad y_{0}+y_{0}^{*}=0.1, \\
& \eta=\eta^{*}=0.5, C_{0}^{*}=0.3
\end{aligned}
$$

(Notice that because the two countries have the same homothetic preferences, the distribution of the initial endowments between them is irrelevant for the equilibrium prices.) 